\title{
Low Doses of a PCB (Aroclor 1254) Affect the Body Weight by Decreasing the Activity of Glucose-6-Phosphatase in the Liver and Kidney Cells of Mice
}

\author{
Shweta Pathak ${ }^{1}$, Rahul Kundu ${ }^{1}$ \\ ${ }^{1,1}$ Department of Biosciences, Saurashtra University, Rajkot-360005, Gujarat State, India
}

\begin{abstract}
In this communication, toxicity of very low doses of Aroclor 1254, the most potent PCB, was evaluated in respect to gross body weight and glucose-6-phosphatase (G6Pase) activity in liver and kidney cells of mice. The study was designed to test three hypotheses. Groups of adult male Swiss albino mice were subjected to two very low and environmentally available doses $(0.1 \& 1 \mathrm{mg} / \mathrm{kg} \mathrm{bw} / \mathrm{d})$ of Aroclor 1254 exposed for three durations $(4,8 \& 12 d)$. The toxicant was administered orally and the specific activity of glucose-6phosphatase was estimated from the liver and kidney cells of mice. The doses selected were significantly lower than the lethal dose but comparable to possible human exposure from different sources. The results revealed significant dose and exposure duration dependent effects of Aroclor on total body weight and the activity of glucose-6-phosphatase in liver and kidney cells of mice. The observed results suggested that all three hypotheses were true. It may be possible that the activation of AhR mediates the suppression of body weight and the activity of glucose-6-phosphatase, which suggested a role for these pollutants as disruptors of energy metabolism.
\end{abstract}

Keywords - Aroclor 1254, Glucose-6-phosphatse, Mice, Liver, Kidney.

\section{INTRODUCTION}

Polychlorinated biphenyls (PCBs) are one of the major persistent organic pollutants (POPs). There are 209 PCB congeners are categorized based on the number of chlorine atoms in the compound. A common classification divides PCBs into dioxin-like and nondioxin-like based on their structural and toxicological similarity with the dioxin molecule [1]. These compounds are physically, thermally and chemically stable and thus, used in a variety of industrial applications [2]. PCBs have the tendency to bioaccumulate, bioconcentrate and biomagnify in the tissues of humans and animals which is a matter of serious concern. Because of improper and careless waste disposal properties living beings are easily exposed to this compound [2]. Exposure to PCBs is responsible for variety of adverse effects such as wasting syndrome, immunotoxicity, skin disorders, neurological, metabolic, endocrine and reproductive effects in both humans and animals [2]. Some of these effects have been confirmed by laboratory experiments and include progressive weight loss ('wasting syndrome'), alteration of lipid metabolism, hepatotoxicity, immunotoxicity, alteration of endocrine system function and reproduction, teratogenicity and developmental toxicity, and tumor promotion [3- 8]. The mechanism of toxicity indicate that some of the PCB congeners act by the same mechanism as the chlorinated dioxins i.e., the toxicity is probably facilitated through the interaction with the Ah receptor. One of the major devastating effects of AHR activation by TCDD is lethal wasting syndrome in which decreased liver gluconeogenesis and body weight are prominent features [9, 10]. It produces the starvation-like state in which gluconeogenesis and food intake decreased. Therefore, the aim of the present study was to evaluate the in vivo toxic effect of different sublethal doses and exposure durations of Aroclor 1254 on body weight and the activity of glucose-6-phosphatase in liver and kidney cells of mice. The study was designed to test three hypotheses (a) toxicity of Aroclor 1254 suppresses the body weight of mice due to inhibition in the activity of glucose-6phosphatase, (b) if so, than it will exhibit a typical dose-duration response and, (c) since the functionality of G6Pase is maximum in liver, toxic effect of Aroclor 1254 will be more in liver than kidney.

\subsection{Reagents}

\section{Materials and Methods}

The PCB used in this study, Aroclor 1254, was procured from Sigma-Aldrich Chemicals Ltd. (CAS No. 11097-69-1). All other chemicals and reagents were of analytical grade and also procured from the Sigma Chemical Co. (St. Louis, MO, USA) for the assessment of glucose-6-phosphatase in liver and kidney of mice. 


\subsection{Animals}

Male Swiss albino mice (30-40 g) were kept in the animal house facilities at prescribed conditions as per CPCSEA, India. Animals were given commercially available rodent diet and water ad libitum. Different animal groups for the experiments were kept in a standardized conditions $\left(26 \pm 2{ }^{\circ} \mathrm{C} ; 44-55 \% \mathrm{RH}, 10: 14 \mathrm{~h}\right.$ light and dark cycles) for one week before the experiment [11]. All studies were conducted according to the ethical norms approved by the CPCSEA, India (CPCSEA/CH/RF/ACK-2003, 29-07-2003).

\subsection{Experimental design and treatments}

A total of 63 adult male Swiss albino mice were used for the study. The selection of the doses were based on the (a) available reports of the doses causing non-carcinogenic effects in the liver and kidney tissue of mice, especially on the enzymes (acute to sub-acute exposure), and (b) evaluation of toxicity studies and application of factors (LOAEL) for extrapolating from animal model to human for Aroclor 1254 administered through oral route [12]. The doses selected therefore, were very low concentrations of Aroclor 1254, comparable to that of a possible human exposure from different environmental sources. Different groups of mice were given oral administration of Aroclor $1254(0.1$ and $1 \mathrm{mg} / \mathrm{kg}$ body weight $/ \mathrm{d})$ dissolved in corn oil (vehicle) for three different exposure durations of 4,8 and 12 days.

\subsection{Tissue preparation}

After completion of toxic exposure, the liver and kidney was rapidly removed and washed in ice-cold Sucrose - EDTA - Imidazole buffer (SEI buffer). Known amount of tissue was homogenized using PotterElvehjem glass homogenizer to make a $10 \%(\mathrm{w} / \mathrm{v})$ tissue concentration. The tissue preparation and enzyme extraction procedure were as per the method of Zaugg [13] with appropriate modifications.

\subsection{Evaluation of Glucose-6-phosphatase activity}

Activity of Glucose-6-phosphatase was estimated by the method of Shimeno [14] with some appropriate modifications [15] and inorganic phosphate was measured by the method of Fiske and Subbarow [16]. To calculate the specific activities of the enzymes studied, protein content of each sample was estimated as per the method of Lowry et al. [17] using Folin phenol reagent and bovine serum albumin as the standard.

\subsection{Statistical analyses}

The obtained data were subjected to various statistical analyses for their cumulative acceptability and for testing the hypotheses formulated. Comparison between control and doses were made using one-way ANOVA. A two-way nested ANOVA was done to check the significance in the variations between different doses and amongst different exposure durations. In addition to those tests, Comparison for the significance variations between control and each durations within a given dose were performed using two-tailed Student's ' $\mathrm{t}$ ' test. All statistical procedures were done as per Sokal and Rohlf [18].

\section{Results and Discussion}

Results of the present study showed noticeable reduction in the body weight of mice in all the doses and exposure durations. However, more effect was observed in higher dose and exposure duration (Fig.1). Similar results were also observed in the specific activity of glucose-6-phosphstase. It showed a clear dose and duration dependent inhibitory trend in liver and kidney cells of mice for both the doses and exposure durations. Specific activity of glucose-6-phosphatase showed high inhibition in both the doses $(0.1 \& 1 \mathrm{mg} / \mathrm{kg} \mathrm{bw} / \mathrm{d})$ of Aroclor 1254 in all the exposure durations $(4,8 \& 12$ days) but less effects were observed after 4 days of exposure duration (Fig. 2a). In case kidney cells, the specific activity of G6Pase showed the inhibitory trend while, greater inhibition was observed after 12 days exposure (Fig. 2b). Activity glucose-6-phosphatase in liver showed greater inhibition than the kidney.

Dioxins or dioxin-like PCBs have diverse toxic effects all of which require binding to the AHR $[19,20$, $21,22]$. These effects generally include unregulated nutrient metabolism and energy production, immune system dysfunction, carcinogenesis, and cardiac contractile dysfunction [9, 10, 23-25]. PCB-mediated inhibition of gluconeogenesis potentially threatens glucose homeostasis and energy metabolism in exposed humans and animals. PCB-induced disruptions in gluconeogenesis were reported to promote hypoglycemia in susceptible patients during fasting [26]. In human body, only two organs viz., liver and kidney possess sufficient glucogenic enzyme activity and glucose-6-phosphatase activity enabling them to release glucose into the circulation by gluconeogenesis [27]. Glucose-6-phosphatase is widely considered as a key enzyme involved in systemic glucose homeostasis $[28,29]$. The results of this study exhibited a general inhibitory trend in the enzyme activity in liver and kidney of mice. Results of statistical analyses showed the dose and duration dependent effects on the gross body weight and G6Pase enzyme activity. Body weight of mice showed the significant dose 
and duration dependent reduction, as well as an inhibitory trend in the activity of glucose-6-phosphatase in both the selected tissues (Fig. 1, 2 a \& b). No significant variations were observed within each group (Fig. 1, 2 a \& b). Results of two-factor ANOVA showed the exposure duration dependent significant variations in the body weight and activity of glucose-6-phosphatase in liver and kidney, whereas, highly significant variations in the activity of glucose-6-phosphatase were observed in liver cells than kidney (Table-1). The observed results pointed out the possibility of impaired gluconeogenesis and associated decrease in body weight, a possible indicative of wasting effect. It was obvious from the present investigation that both doses of Aroclor 1254 had the immediate effects on the activity of glucose-6-phosphatase but higher dose showed more effect in the enzyme activity than the lower dose. Results of Student's t-test showed highly significant variations in the activity of glucose-6-phosphatase between exposure durations within each dose (Table 2). Similar kind of results was also observed in one-way ANOVA between individual exposure duration within each group (Table 3). All three statistical analyses showed the significant variations in the body weight of mice as compared to control (Table- 1, 2 \& 3). In mammalian liver, TCDD is known to decrease the expression and activity of PEPCK and G6Pase, enzymes that mainly control gluconeogenic flux [10, 30-32]. However, the exact mechanism for these effects remains obscure $[19,20]$. This effect of PCB raises the new possibility that the AHR may contribute the disturbances in glucose homeostasis.

The present investigation reports dose and exposure duration dependent decline in the body weight and specific activity of glucose-6-phosphatase greater in liver than kidney cells of mice after in vivo PCB exposure. As the majority of the studies pertaining to the metabolic effects of dioxin exposure use animal models mostly rodents, broad strain and species specificity demonstrates the sensitivity to wasting effect of dioxins [33, 34, 30, 35-38]. Many observations across such studies include impaired gluconeogenesis, decrease in body weight, and reductions in the glucose-6-phosphatase activity and gene expression of PEPCK [35, 32, 40, 10, 39]. In the given broader distribution, and environmental contamination by, PCBs, compared to TCDD [41,42], the effects of PCB on hepatic and renal glucose metabolism are potentially important.

\section{Figures and Tables}

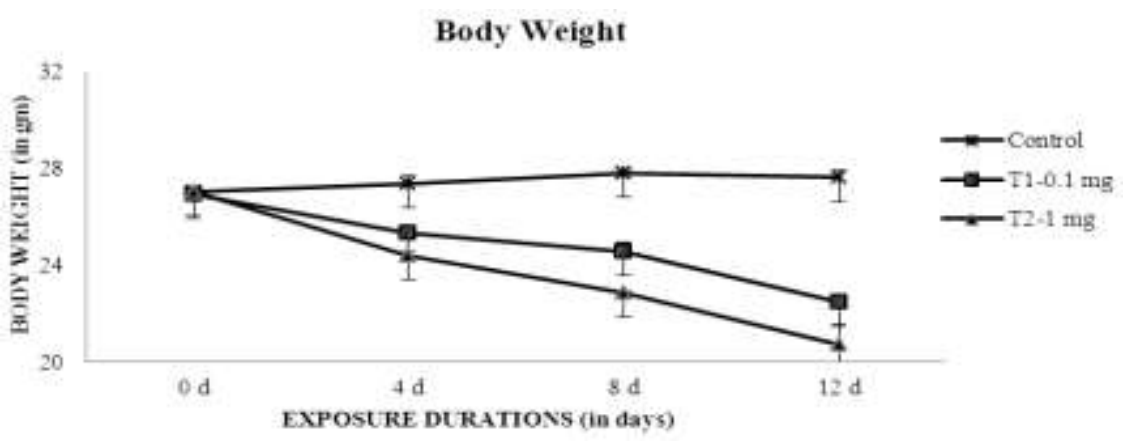

Fig. 1. Graphs showing dose and duration dependent alterations in the body weight after in vivo Aroclor 1254 intoxication. Error bars represent the standard deviation and ' $*$ ' sign represents the significant variations at $\mathrm{P}=$ 0.05 level in the body weight of mice.

TABLE 1. Result of Two-Factor ANOVA between control and toxicated groups in liver and kidney of the adult male albino mice. The results of two-factor ANOVA showed the significant time dependent toxic effects of Aroclor 1254.

\begin{tabular}{|c|c|c|c|}
\hline & Body Wt. & Liver & Kidney \\
\hline Amongst doses & 1.27 & 1.21 & 0.76 \\
\hline Within durations & $23.25^{*}$ & $19.90^{*}$ & $24.73^{*}$ \\
\hline
\end{tabular}

* Significant at $\mathrm{P}=0.05(F$ crit $(d f=3,8)=3.01)$

* Significant at $\mathrm{P}=0.05(F$ crit $(d f=8,35)=2.36)$ 


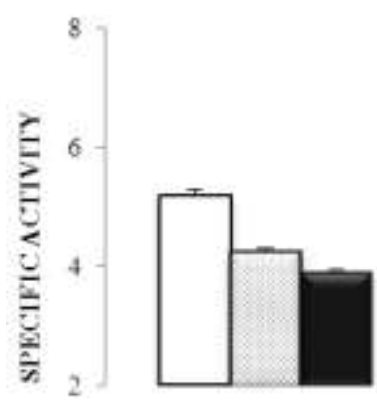

(a) Liver

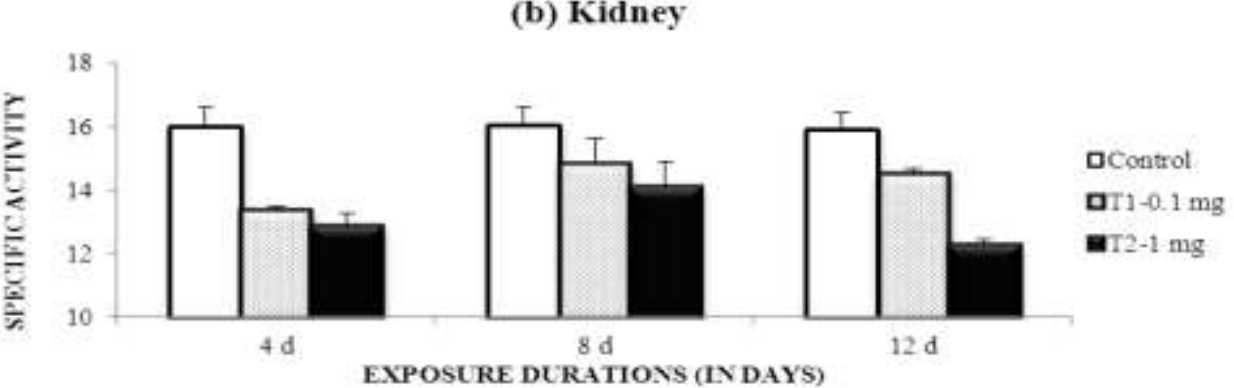

Fig. 2. Graphs showing the dose and duration dependent alterations in the specific activity of Glucose-6phosphatases after Aroclor 1254 intoxication. The error bars represents the standard deviation and '*' sign represents the significant variations at $\mathrm{P}=0.05$ level in the activity of Glucose-6-phosphatases in tissues concern.

TABLE-2. Result of t-test between control and individual exposure duration within each dose in liver and kidney of the adult male albino mice. The statistical analysis showed that all the selected tissues were significantly affected by the Aroclor 1254 intoxication.

\begin{tabular}{|c|c|c|c|c|c|c|}
\hline & \multicolumn{2}{|c|}{ Body Wt. } & \multicolumn{2}{c|}{ Liver } & \multicolumn{2}{c|}{ Kidney } \\
\hline & 0.1mg & 1mg & 0.1mg & 1mg & 0.1mg & 1mg \\
\hline 4DAYS & $11.88^{*}$ & $17.41^{*}$ & $25.23^{*}$ & $37.78^{*}$ & $7.69^{*}$ & $7.83^{*}$ \\
\hline 8DAYS & $14.55^{*}$ & $50.67^{*}$ & $79.15^{*}$ & $16.22^{*}$ & 2.38 & $3.82^{*}$ \\
\hline 12DAYS & $33.12^{*}$ & $16.51^{*}$ & $44.52^{*}$ & $54.63^{*}$ & $4.92^{*}$ & $12.36^{*}$ \\
\hline
\end{tabular}

*Significance at $\mathrm{P}=0.05$ ( T crit. $=2.447, d f=6$ )

TABLE -3. Result of Single factor ANOVA between individual exposure durations within each group in liver and kidney of the adult male albino mice. Results showed the significant variations in the selected tissues in both the doses.

\begin{tabular}{|c|c|c|c|}
\hline & Body Wt. & Liver & Kidney \\
\hline CONTROL & 2.85 & 0.60 & 0.04 \\
\hline 0.1MG & $16.73^{*}$ & $11.41^{*}$ & $9.43^{*}$ \\
\hline 1MG & $60.23^{*}$ & $29.48^{*}$ & $10.84^{*}$ \\
\hline
\end{tabular}

*Significance at $\mathrm{P}=0.05(F$ crit $.=4.26, \mathrm{df}=2,9)$

\section{CONCLUSIONS}

The overall results of the present study showed that even a very low dose (10,000 and 1000 times lower dose than the $\mathrm{LD}_{50}$ value for mice) of Aroclor 1254 had the effect on the body weight of mice and on the activity of glucose-6-phosphatase in liver and kidney of mice. This finding answers the hypotheses that (a) toxic effect of Aroclor 1254 did decrease the body weight of mice which was possibly due to inhibition in the activity of glucose-6-phosphatase, (b) the observed effects on the body weight and activity of glucose-6-phospahtase was a dose and exposure duration dependent response and, (c) toxic effect of Aroclor 1254 was more significantly inhibited the activity of glucose-6-phosphatase in liver than kidney. One of the major possibilities of direct toxic effect of PCB was that it activated the AhR receptor which ultimately lead to the wasting 
syndrome in which decreased liver gluconeogenesis and body weight are noticeably effected. This situation produced the starvation-like state in which gluconeogenesis and food intake decreased.

\section{Acknowledgements}

Authors are thankful to UGC, Govt. of India, New Delhi for supporting this study through its DSA / CAS Programme. UGC is also thankfully acknowledged for a Meritorious Research Fellowship awarded to the senior author.

\section{REFERENCES}

[1.] Agency for Toxic Substances and Disease Registry, Polychlorinated Biphenyls (PCB's): Toxicological Profile, 2000, http:// www.atsdr.cdc.gov/toxprofiles/tp17.html.

[2.] WHO, Polychlorinated biphenyls: human health aspects. Geneva, Switzerland: World Health Organization, 2003, pp 1-64

[3.] E.M. Foekema, C.M. Deerenberg, and A.J. Murk, Prolonged ELS test with the marine flatfish sole (Solea solea) shows delayed toxic effects of previous exposure to PCB 126, Aquatic Toxicology 90, 2008, 197-203.

[4.] E. Monosson, Reproductive and developmental effects of PCBs in fish: a summary of laboratory and field studies, Reviews in Toxicology 3, 1999/2000, 25-75.

[5.] G. Ross, The public health implications of polychlorinated biphenyls (PCBs) in the environment, Ecotoxicology and Environmental Safety 59, 2004, 275-291.

[6.] S. Safe, Clinical correlates of environmental endocrine disruptors, Trends in Endocrinology and Metabolism 16, 2005, 139-144.

[7.] L.M. Schell, M.V. Gallo, Relationships of putative endocrine disruptors to human sexual maturation and thyroid activity in youth, Physiol Behav 99, 2010, 246-253.

[8.] V. Van Ginneken, A. Palstra, P. Leonards, M. Nieveen, H. van den Berg, G. Flik, T. Spanings, P. Niemantsverdriet, G. van den Thillart, and A. Murk, PCBs and the energy cost of migration in the European eel (Anguilla anguilla L.), Aquatic Toxicology 92, 2009, 213-220.

[9.] A. Poland, and J.C. Knutson, 2,3,7,8-Tetrachlorodibenzo-thorn-Dioxin and Related Halogenated Aromatic Hydrocarbons: Examination of the Mechanism of Toxicity, Annu. Rev. Pharmacol. Toxicol. 22, 1982, 517-554.

[10.] B.U. Stahl, D.G. Beer, L.W. Weber, and K. Rozman, Reduction of hepatic phosphoenolpyruvate carboxykinase (PEPCK) activity by 2,3,7,8-tetrachlorodibenzo- p-dioxin (TCDD) is due to decreased mRNA levels, Toxicology 79, 1993, 81-95.

[11.] L.F.M. Van Zutphen, V. Baumans, A.C. Beyners, Principles of Laboratory Animals Science, 1993.

[12.] ATSDR, Toxicological Profile for Polychlorinated Biphenyls. Draft for Public Comment (Update). Prepared by Research Triangle Institute, under Contract No. 205-93-0606 for ATSDR, Public Health Service, U.S. Department of Health and Human Services, 1995.

[13.] W.S. Zaugg, 1982. A simplified preparation for ATPase determination in gill tissue. Can. J. Fish Aquatic Sci. 39(1), 1982, $215-217$.

[14.] S. Shimeno, Properties and distribution of glucose-6-phosphatase. In: Shimeno, S., ed. Studies on Carbohydrate Metabolism in Fish American Publishing Company Pvt. Ltd., New York, 1982, pp.1-16.

[15.] S. Pathak, R. Kundu, Short-term PCB (Aroclor 1254) toxicity on few phosphatases in mice brain, Dose Response, 2011, DOI: 10.2203/dose-response.10-037.Kundu.

[16.] C.F. Fiske, Y. Subbarow, The colorimetric determination of phosphorus, J. Biol. Chem. 66, 1925, 375-400.

[17.] O.H. Lowry, N.J. Rosebrough, A.L. Farr, R.J. Randall, Protein measurement with the Folin-phenol reagent, J. Biol. Chem. 193, $1951,265-275$.

[18.] Sokal, R.R., Rohlf, F.J., 1969. Biometry. W.H. Freeman and Company. San Francisco, 1969, pp.26

[19.] A.B. Okey, An AH receptor odyssey to the shores of toxicology: The Deichmann lecture-International Congress of ToxicologyXI, Toxicol. Sci. 98, 2007, 5-38.

[20.] Y.Z. Gu, J.B. Hogenesch, and C.A. Bradfield, The PAS Superfamily: Sensors of Environmental and Developmental Signals, Annu. Rev. Pharmacol. Toxicol. 40, 2000, 519-561.

[21.] L.P. Nguyen, and C.A. Bradfield, The search of endogenous activators of the Aryl hydrocarbon receptor, Chem. Res. Toxicol. 21, 2008, 102-116.

[22.] P.M. Fernandez-Salguero, D.M. Hilbert, S. Rudikoff, J.M. Ward, and F.J. Gonzalez, Aryl-hydrocarbon receptor- deficient mice are resistant to ). 2,3,7,8-tetrachlorodibenzo-p-dioxin induced toxicity. Toxicol. Appl. Pharmacol. 140, 1996, 173-179.

[23.] L. Canga, L. Paroli, T.J. Blanck, R.B. Silver, and A.B. Rifkind, A. B., 2,3,7,8-tetrachlorodibenzo-p-dioxin increases cardiac myocyte intracellular calcium and progressively impairs ventricular contractile responses to isoproterenol and to calcium in chick embryo hearts, Mol. Pharmacol. 44, 1993, 1142-1151.

[24.] H.G. Shertzer, M.B. Genter, D. Shen, D.W. Nebert, Y. Chen, and T.P. Dalton, TCDD decreases ATP levels and reactive oxygen production through changes in mitochondrial F0F1-ATP synthase and ubiquinone, Toxicol. Appl. Pharmacol. 217, 2006, 363-374.

[25.] A.B. Rifkind, CYP1A in TCDD Toxicity and in Physiology-with Particular Reference to CYP Dependent Arachidonic Acid Metabolism and other Endogenous Substrates, Drug. Metab. Rev. 38, 2006, 291-335.

[26.] W. Zhang, R.M. Sargis, P.A. Volden, C.M. Carmean, X.J. Sun, andM.J. Brady, PCB 126 and Other Dioxin-Like PCBs Specifically Suppress Hepatic PEPCK Expression via the Aryl Hydrocarbon Receptor, 2012, PLoS ONE 7(5): e37103. doi:10.1371/journal.pone.0037103.

[27.] C. Meyer, J. Gerich, Role of the human kidney in glucose homeostasis, Curr. Opin. Endocrinol. Diabetes 7, 2000, 19-24.

[28.] R.C. Nordlie, Glucose-6-Phosphatase Phosphotransferase: Roles and Regulation in Relation to Gluconeogenesis. New York, John Wiley, 1976, p. 53-152.

[29.] G. Mithieux, New knowledge regarding glucose-6-phosphatase gene and protein and their roles in glucose metabolism, Eur. J. Endocr. 136, 1997, 137-145.

[30.] M.T. Hsia, and B.L. Kreamer, Delayed wasting syndrome and alterations of liver gluconeogenic enzymes in rats exposed to the TCDD congener 3, 39, 4,49- tetrachloroazoxybenzene, Toxicol. Lett. 25, 1985, 247-258.

[31.] F. Fan, and K.K. Rozman, relationship between acute toxicity of 2,3,7,8-tetrachlorodibenzo-p-dioxin (tcdd) and disturbance of intermediary metabolism in the long-evans rat, Arch. Toxicol. 69, 1994, 73-78.

[32.] L.W. Weber, M. Lebofsky, B.U. Stahl, J.R. Gorski, G. Muzi, and K. Rozman, Reduced activities of key enzymes of gluconeogenesis as possible cause of acute toxicity of 2,3,7,8-tetrachlorodibenzo-p-dioxin (TCDD) in rats, Toxicology 661, 1991, $33-144$. 
[33.] M. Viluksela, M. Unkila, R. Pohjanvirta, J.T. Tuomisto, B.U. Stahl, et al., Effects of 2,3,7,8-tetrachlorodibenzo-p-dioxin (TCDD) on liver phosphoenolpyruvate carboxykinase (PEPCK) activity, glucose homeostasis and plasma amino acid concentrations in the most TCDD-susceptible and the most TCDD resistant rat strains, Arch. Toxicol. 73, 1999, 323-336.

[34.] M. Viluksela, B.U. Stahl, and K.K. Rozman, Tissue-specific effects of 2,3,7,8-Tetrachlorodibenzo-p-dioxin (TCDD) on the activity of phosphoenolpyruvate carboxykinase (PEPCK) in rats, Toxicol. Appl. Pharmacol. 135, 1995, 308-315.

[35.] L.W. Weber, M. Lebofsky, B.U. Stahl, S. Smith, and K.K. Rozman, Correlation between toxicity and effects on intermediary metabolism in 2,3,7,8-tetrachlorodibenzo- p-dioxin-treated male C57BL/6J and DBA/2J mice, Toxicol. Appl. Pharmacol. 131, $1995,155-162$.

[36.] J.R. Olson, Metabolism and disposition of 2,3,7,8-tetrachlorodibenzo-pdioxin in guinea pigs, Toxicol. Appl. Pharmacol. 85, 1986, 263-273.

[37.] P.A. Harper, C.L. Golas, A.B. Okey, Ah receptor in mice genetically "nonresponsive" for cytochrome P4501A1 induction: cytosolic Ah receptor, transformation to the nuclear binding state, and induction of aryl hydrocarbon hydroxylase by halogenated and nonhalogenated aromatic hydrocarbons in embryonic tissues and cells, Mol. Pharmacol. 40, 1991, 818-826.

[38.] E.E. McConnell, Comparative toxicity of PCBs and related compounds in various species of animals, Environ. Health Perspect. 60, 1985, 29-33.

[39.] Boll M, Weber LW, Messner B, Stampfl A, Polychlorinated biphenyls affect the activities of gluconeogenic and lipogenic enzymes in rat liver: is there an interference with regulatory hormone actions? Xenobiotica 28, 1998, 479-492.

[40.] B.U. Stahl, D.G. Beer, L.W. Weber, M. Lebofsky, K. Rozman, Decreased hepatic phosphoenolpyruvate carboxykinase gene expression after 2,3,7,8- tetrachlorodibenzo-p-dioxin treatment: implications for the acute toxicity of chlorinated dibenzo-p-dioxins in the rat, Arch. Toxicol. Suppl. 15, 1992, 151-155.

[41.] J. Jigyasi, R. Kundu, Low dose TCDD affects membrane bound ion dependent ATPases in mice liver, IOSR Jour. Env. Sci. Tox. Food Tech. 2 ,2013, 15-19.

[42] J. Jigyasi, R. Kundu, Effects of Low Dose Dioxin on Membrane Bound Ion Dependent ATPases in Mice Kidney. IOSR Jour. Env. Sci. Tox. Food Tech. 2 ,2013, 43-48. 